\title{
A rare presentation of an elderly patient with acute lymphocytic leukemia and platelet count of zero associated with ST- elevation myocardial infarction, pulmonary thromboembolism in the setting of SARS- CoV 2: a case report
}

Arash Hashemi ${ }^{1}$, Fady Gerges ${ }^{2 *}$ (D) Haseeb Raza Naqvi ${ }^{3}$, Irina Kotlar ${ }^{4}$, Sara Moscatelli ${ }^{5}$, Ashkan Hashemi ${ }^{6}$, Yasmin Rustamova ${ }^{7}$ and Abdallah Almaghraby ${ }^{8}$

\begin{abstract}
Background: Novel coronavirus disease 2019 (COVID-19) is known to lead not only to severe acute respiratory syndrome, but also can result in thromboembolic events in both the venous and the arterial circulation by inducing coagulation disorders. The potential causes of coagulopathy are inflammation, platelet activation, endothelial dysfunction, and stasis. The thrombotic events including pulmonary embolism, deep venous thrombosis as well as intracatheter thrombosis are more likely to develop in patients infected with severe form of SARS-CoV-2 who are admitted to ICU. Furthermore, these events contribute to multi-organ failure.

Case presentation: Herein, we report a case of an immunocompromised COVID-19 elderly patient with acute lymphocytic leukemia who developed myocardial infarction with ST elevation in the setting of acute pulmonary thromboembolism in the presence of zero platelet count. Despite successful urgent coronary revascularization and platelet transfusion, the patient eventually died after failed resuscitation efforts.
\end{abstract}

Conclusion: Patients with COVID-19 infection are at a greater risk of developing cardiovascular complications, but their appropriate management can decrease the risk of fatal events. Coronary thrombosis associated with pulmonary thromboembolism in the setting of thrombocytopenia is a rare and a complex to manage condition. Significance of single antiplatelet agent in STEMI with thrombocytopenia merits further studies. According to expert opinions and literature reviews, we must avoid dual antiplatelet therapy in these patients and keep platelet transfusion as a standard therapy to avoid drastic bleeding complications.

\footnotetext{
*Correspondence: dr_fadyaziz@hotmail.com; fady.gerges@mediclinic.ae

2Department of Cardiovascular Science, Mediclinic Al Jowhara Hospital, P.O.

box 84142 Al Ain, United Arab Emirates

Full list of author information is available at the end of the article
}

(c) The Author(s). 2021 Open Access This article is licensed under a Creative Commons Attribution 4.0 International License which permits use, sharing, adaptation, distribution and reproduction in any medium or format, as long as you give appropriate credit to the original author(s) and the source, provide a link to the Creative Commons licence, and indicate if changes were made. The images or other third party material in this article are included in the article's Creative Commons licence, unless indicated otherwise in a credit line to the material. If material is not included in the article's Creative Commons licence and your intended use is not permitted by statutory regulation or exceeds the permitted use, you will need to obtain permission directly from the copyright holder. To view a copy of this licence, visit http://creativecommons.org/licenses/by/4.0/. 


\section{Background}

COVID-19 patients with associated venous thromboembolism can eventually develop STEMI requiring urgent revascularization. Despite this fact, the presentation of patients with STEMI during pandemic time was reduced, probably due to quarantine and social isolation. The most frequently reported abnormalities in coagulation profile in these patients are increased D-dimer, thrombocytopenia, and prolongation in thrombin time. Severe thrombocytopenia furthermore worsens the prognosis and suggests the presence of additional etiologies. Coexistence of all three patterns in a COVID-19 patient is a rare condition. Overlapping of clinical manifestations additionally complicates the initial diagnosis.

\section{Case presentation}

An elderly 70-year-old female patient was hospitalized for receiving her regular chemotherapy dose and with no specific complaints.

She reports history of diabetes mellitus (DM), hypertension (HTN), and on chemotherapy treatment for acute lymphocytic leukemia (ALL) including vincristine and idarubicin.

During admission, regular PCR screening for SARSCoV-2 came positive.

On day two of admission, patient developed dry cough and chest pain and acute dyspnea.
On physical examination, patient was afebrile, however, looked weak and fragile with dyspnea NYHA class III. She had mild petechiae and ecchymosis on lower limbs.

Blood pressure was 105/70 $\mathrm{mm} \mathrm{Hg}$, pulse was equal on both sides with heart rate of $90 \mathrm{bpm}$, respiratory rate $30 / \mathrm{min}$, and oxygen saturation $\left(\mathrm{SpO}_{2}\right) 92 \%$ at room air.

There were no cardiac murmurs on cardiac auscultation.

Chest examination revealed coarse crackles on both lungs.

Investigations including lab and imaging were as follows:

Electrocardiogram (ECG) showed normal sinus rhythm with a rate of $95 \mathrm{bpm}$

Computed tomographic pulmonary angiography

(CTPA) showed picture of acute pulmonary

thromboembolism (PTE) involving subsegmental

branches of both lower lung lobes. CT depicted

subpleural ground glass opacities as well on both lungs

(Fig. 1).

Fasting blood sugar, 189

Serum creatinine, $0.95 \mathrm{mg} / \mathrm{dL}$

Creatine phosphokinase, $500 \mathrm{IU} / \mathrm{L}$

Creatine kinase myocardial band (CK-MB), 75 IU/1

Serum potassium (K), $4.4 \mathrm{mEq} / \mathrm{L}$

Serum sodium $(\mathrm{Na}), 138 \mathrm{mEq} / \mathrm{L}$

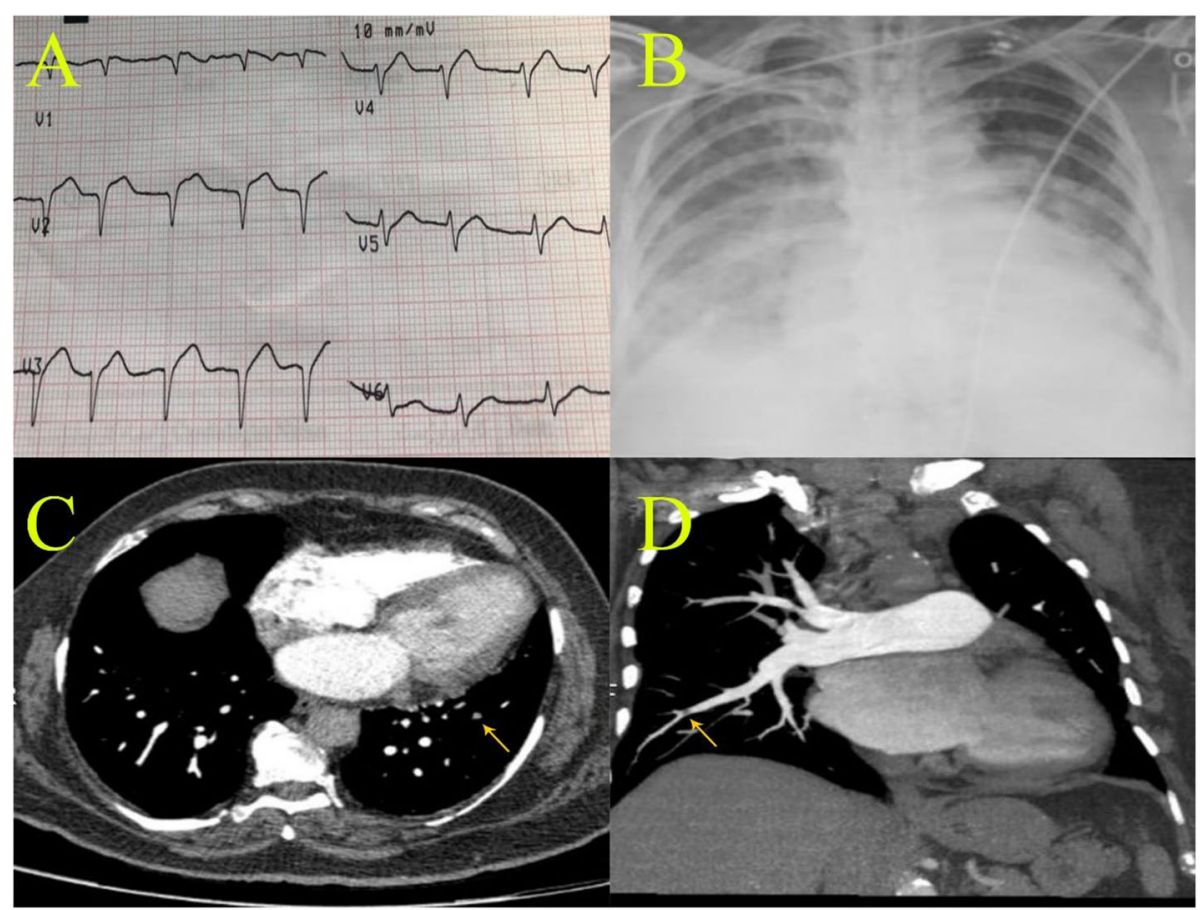

Fig. 1 (Panel a) ECG showing atrial fibrillation rhythm and Q waves with residual ST elevation in the anterior chest leads, (panel b) chest X-ray showing increased cardiac shadow with bilateral lung infiltrations with classic ground glass opacities, (panels c and d) MSCT pulmonary angiography showing a picture of acute pulmonary thromboembolism (PTE) involving subsegmental branches of both lower lung lobes (yellow arrows) 
Prothrombin time (PT), $17 \mathrm{~s}$ (normal 12-14 s)

Partial thromboplastin time (PTT), $48 \mathrm{~s}$ (normal 25-35 s)

International normalized ratio (INR), 1.5

Hemoglobin, $8 \mathrm{~g} / \mathrm{dl}$

WBC, $2.0 \times 1000 / \mathrm{Ul}$

Hematocrit, $24 \%$

Platelet count (PLT), $0 \times 10^{9}$ per/L (recorded zero by lab)

Lymphocytes, $61 \%$

COVID-19 IgM 0.10 (positive >1.1)

COVID-19 IgG 3.45 (positive $>1.1$ )

D-dimer $>10,000 \mu \mathrm{g} / \mathrm{L}$

Echocardiography (Echo): mild left ventricular (LV) dysfunction with LV ejection fraction (EF) 55\%. Mildly enlarged right ventricle with normal pulmonary

pressure. No resting wall motion abnormality.

Pelvi-abdominal ultrasound abdomen: dilated inferior

vena cava $24 \mathrm{~mm}$ with right kidney larger than normal with a size of $145 \mathrm{~mm}$.

Chest X-ray: bilateral lung infiltrations with classic ground glass opacities.

Cardiac and hematologic team together decided not to start anti-coagulation for her PTE because the patient's platelet (PLT) count was $0 \times 10^{9} \mathrm{per} / \mathrm{L}$ after repeating twice, supposedly due to chemotherapyinduced thrombocytopenia (CIT); however, disseminated intravascular coagulation (DIC) cannot be ruled out especially in presence of high $\mathrm{D}$-dimer and prolonged PT and aPTT. In addition, patient was hemodynamically stable, and hence, we have not opted for anti-coagulation.

Patient started to be hypoxic with $\mathrm{SpO}_{2} 89 \%$; however, blood pressure was maintained at normal values. Hypoxia improved on supplemental oxygen.

Urgent transfusion of random donor platelets and fresh frozen plasma was done.

On day three of admission, patient developed excruciating central chest pain with raised ST segment on ECG.

Via a trans-radial access through a 4-French size sheath, primary percutaneous coronary intervention (PCI) to left anterior descending artery (LAD) was performed.

Before PCI, elective endotracheal intubation was done to prevent nasogastric blood aspiration resulted from iatrogenic severe epistaxis induced by nasogastric tube insertion.

Our priority during PCI was to achieve successful revascularization through performing only plain old balloon angioplasty (POBA) without using a coronary stent to avoid starting dual antiplatelet therapy (DAPT) for the patient in view of her severe thrombocytopenia.

However, after multiple runs of thrombosuction to remove the heavy thrombus burden followed by POBA, we encountered abrupt reclosure of the LAD artery and no-reflow phenomenon with continuous reformation of coronary thrombi. Accordingly, we had to deploy the newest second-generation drug-eluting stent (DES) with optimal results and TIMI (thrombolysis in myocardial infarction) grade III flow with full resolution of chest pain.

Patient received total of 20 units of platelets, after which PLT count improved to $20 \times 10^{9} \mathrm{per} / \mathrm{L}$.

During PCI, patient developed rapid atrial fibrillation (AF) that responded successfully to $150 \mathrm{mg}$ intravenous bolus dose of amiodarone with reversion to sinus rhythm.

INR was 1.5, and active clotting time (ACT) during PCI was $381 \mathrm{~s}$ without anti-coagulants which posed an extremely high risk of bleeding. Hence, no anticoagulant was given during or after the PCI procedure.

Medications during admission were as follows:

Remdesivir loading dose of $200 \mathrm{mg}$ IV infused over 30$120 \mathrm{~min}$ on day 1 , then day 2 and thereafter, $100 \mathrm{mg}$ IV qDay for total of 7 days.

Meropenem, insulin, ticagrelor, carvedilol, amiodarone, amlodipine, furosemide, $\mathrm{N}$-acetyl cysteine, oral hypoglycemic agents, fentanyl drip, pantoprazole, fresh frozen plasma, random donor platelets transfusion.

During coronary care unit admission, we decided to start ticagrelor as a single anti-platelet agent post-PCI after $180 \mathrm{mg}$ of a loading dose given before PCI.

LVEF improved to $35 \%$ compared to $20 \%$ before PCI.

After ensuring all weaning criteria are present, patient was extubated after 3 days and was more stable in terms of hemodynamics and oxygen saturation.

Moreover, LVEF further improved to $50 \%$ on screening Echo 3 days later. And PLT count increased to $25 \times$ $10^{9} \mathrm{per} / \mathrm{L}$.

However, on day six, the patient's condition quickly deteriorated due to acute severe respiratory failure with hypoxia.

The patient was intubated and mechanically ventilated. However, she had cardiac arrest with pulseless electrical activity and then asystole. Cardiopulmonary resuscitation (CPR) could not revive the patient, and she died.

\section{Discussion}

Cancer patients receiving chemotherapy have a sevenfold higher risk of venous thromboembolism compared with non-cancer patients; furthermore, the estimated rate of thrombocytopenia induced by chemotherapeutic agents can vary between 21 and $70 \%$ [1].

In the era of the COVID-19 pandemic, we as physicians are faced with common cardiovascular adverse events including acute myocardial infarction, venous thromboembolism, heart failure, myocarditis, and arrhythmias. 
Patients with cancer are particularly susceptible to the virus because of the immunosuppressive state, with greater risk from severe COVID-19 illness and death [2].

Furthermore, vascular and systemic inflammation induced by SARS-CoV-2 infection may cause endothelial dysfunction and prothrombotic and hypercoagulable state. Thrombocytopenia due to myelosuppressive chemotherapy needs to be taken into consideration prior to initiation of anticoagulation. By far, it is also known that the virus itself is associated with drop in PLT count [3]. Moreover, the risk of bleeding particularly when PLT count drops below $20 \times 10^{9}$ outweighs the potential benefit of anticoagulant therapy. While large randomized trials for treatment of venous thromboembolism (VTE) and concomitant thrombocytopenia are lacking, expert opinion agrees on withholding anticoagulation and considering the insertion of vena cava filter when the level of PLT is critical [2].

On the other hand, it is quite rare to find a cancer patient presenting with acute coronary syndrome (ACS) and low platelet count. Patients with acute myocardial infarction and thrombocytopenia have a two-fold increase in inhospital mortality and an increased risk of ischemic stroke, cardiogenic shock, and cardiac arrest [4].

Management of ACS in cancer patients with thrombocytopenia is a challenging domain. This challenge is even greater in this patient that has been diagnosed with COVID-19 complicated by acute pulmonary embolism. The use of antiplatelet drugs in patients with ACS and thrombocytopenia always raises a question. In such patients, aspirin administration may be used when platelet counts are $>10,000 / \mathrm{mL}[5]$.

There is a clear medical need for strategies to lower the risk of bleeding in PCI patients, without losing ischemic protection. The results from the TWILIGHT subanalyses offer important insights about ticagrelor as a monotherapy in these high-risk patients [6].

The standard dose of unfractionated heparin in patients undergoing percutaneous coronary intervention (PCI) in case of severe thrombocytopenia is $30-50 \mathrm{U} / \mathrm{kg}$. Further dose adjustment can be done to keep activated clotting time (ACT) not less than $250 \mathrm{~s}$ [5]. The safety of antiplatelet therapy and PCI in patients who have ACS and thrombocytopenia is unknown because there are no randomized studies to suggest treatment approaches in such patients.

According to the guidelines provided by the American Society of Clinical Oncology, thrombocytopenic patients with the platelet count of 40,000 to $50,000 / \mathrm{mL}$ can undergo any invasive procedure, but in case of intraoperative or postoperative bleeding, platelets can be transfused accordingly [7]. Prophylactic platelet transfusion is not recommended in patients undergoing cardiac catheterization with thrombocytopenia, unless:
1. Platelet count $<20,000 / \mathrm{mL}$ and one of the following: (a) high fever, (b) leukocytosis, (c) rapid fall in platelet count, (d) other coagulation abnormality.

2. Platelet count $<20,000 / \mathrm{mL}$ in solid tumor patients receiving therapy for bladder, gynecologic, or colorectal tumors; melanoma; or necrotic tumors [8].

Regarding revascularization in patients presenting with acute myocardial infarction and thrombocytopenia, POBA should be reserved for patients with platelet count $<30,000 / \mathrm{ml}$. Balloon angioplasty might be the treatment of choice also because the duration of DAPT can be limited to 2 weeks. Bivalirudin and/or radial approach should be considered to minimize the risk of bleeding [5].

\section{Conclusions}

The increased risk of thrombotic complications is well recognized in patients affected by the SARS-CoV-2 virus. Management of PTE and STEMI in COVID-19 patient with cancer and thrombocytopenia is extremely complex and challenging and is associated usually with a grave prognosis.

Patients who suffer from malignant diseases are more prone to develop severe form of infection and complications from SARS-CoV-2 virus. Treatment of venous and arterial thrombosis in cancer patients with thrombocytopenia poses a challenge.

Further studies are expected to answer the questions regarding the optimal anticoagulant and anti-platelet for these patients' subsets.

\section{Abbreviations}

ACS: Acute coronary syndrome; ACT: Active clotting time; AF: Atrial fibrillation; ALL: Acute lymphocytic leukemia; CIT: Chemotherapy-induced thrombocytopenia; CK-MB: Creatine kinase myocardial band; CPR: Cardiopulmonary resuscitation; CTPA: Computed tomographic pulmonary angiography; DAPT: Dual antiplatelet therapy; DES: Drug-eluting stent; DIC: Disseminated intravascular coagulation; DM: Diabetes mellitus; ECG: Electrocardiogram; Echo: Echocardiography; EF: Ejection fraction; HTN: Hypertension; INR: International normalized ratio; K: Potassium; LAD: Left anterior descending artery; LV: Left ventricular; Na: Sodium; PCI: Percutaneous coronary intervention; PLT: Platelet count; POBA: Plain old balloon angioplasty; PT: Prothrombin time; PTE: Pulmonary thromboembolism; PTT: Partial thromboplastin time; $\mathrm{SpO}_{2}$ : Oxygen saturation; TIMI: Thrombolysis in myocardial infarction; VTE: Venous thromboembolism

\section{Acknowledgements}

Not applicable

\section{Authors' contributions}

$\mathrm{AH}$, the main author, was the major contributor in writing the manuscript. FG contributed to revising manuscript, modifying discussion, and revising English language. HR contributed to writing the abstract and revising the discussion. IK contributed to extensive search on literature for writing the discussion. SM shared in writing the conclusion and revising the manuscript. $\mathrm{AH}$ contributed to writing the patient's events and investigations done. YR contributed to modifying the abstract and the title of the manuscript and shared in writing the discussion. AA contributed to finalizing the structure of 
the abstract and manuscript. All authors read and approved the final manuscript

\section{Funding}

No funding was received.

\section{Availability of data and materials}

The data is available for sharing.

\section{Declarations}

\section{Ethics approval and consent to participate}

The corresponding author had a written consent of the patient's first-degree relative to use the data for publication.

\section{Consent for publication}

The corresponding author had a written consent of the patient's first-degree relative to use the data for publication.

\section{Competing interests}

The authors declare that they have no competing interest.

\section{Author details}

${ }^{1}$ Department of Cardiology, Erfan General Hospital, Tehran, Iran. ${ }^{2}$ Department of Cardiovascular Science, Mediclinic Al Jowhara Hospital, P.O. box 84142 Al Ain, United Arab Emirates. ${ }^{3}$ Department of Cardiac Electrophysiology, Mukhtar A. Sheikh Hospital, Multan, Pakistan. ${ }^{4}$ Cardiology Department, University Clinic of Cardiology, Skopje, North Macedonia. ${ }^{5}$ Pediatric Cardiology Services, Royal Brompton Hospital and Harefield NHS Foundation Trust, London, UK. ${ }^{6}$ Department of Cardiology, Sina Hospital, Tehran University of Medical Sciences, Tehran, Iran. 'Department of Cardiology, Azerbaijan Medical University, Baku, Azerbaijan. ${ }^{8}$ Department of Cardiology, University of Alexandria, Alexandria, Egypt.

Received: 6 January 2021 Accepted: 16 April 2021

Published online: 01 May 2021

\section{References}

1. Sreh A, Nakeshree S, Krishnasamy SK, Alfasi N (2018) Therapeutic challenges in the management of acute pulmonary embolism in a cancer patient with chemotherapy-induced thrombocytopenia. Eur J Case Rep Intern Med 5(1): 000713. https://doi.org/10.12890/2017_000713

2. Zhang L, Zhu F, Xie L et al (2020) Clinical characteristics of COVID-19infected cancer patients: a retrospective case study in three hospitals within Wuhan, China. Ann Oncol. https://doi.org/10.1016/j.annonc.2020. 03.296

3. Lippi G, Plebani M, Henry BM (2020) Thrombocytopenia is associated with severe coronavirus disease 2019 (COVID-19) infections: a meta-analysis. Clin Chim Acta 506:145-148. https://doi.org/10.1016/j.cca.2020.03.022. Epub 2020 Mar 13

4. Rubinfeld GD, Smilowitz NR, Berger JS, Newman JD (2019) Association of thrombocytopenia, revascularization, and in-hospital outcomes in patients with acute myocardial infarction. Am J Med 132(8):942-948.e5. https://doi. org/10.1016/j.amjmed.2019.04.003

5. Hiescu CA, Grines CL, Herrmann J, Yang EH, Cilingiroglu M, Charitakis K, Hakeem A, Toutouzas KP, Leesar MA, Marmagkiolis K (2016) SCAl expert consensus statement: evaluation, management, and special considerations of cardio-oncology patients in the cardiac catheterization laboratory (endorsed by the Cardiological Society of India, and Sociedad Latino Americana de Cardiologia intervencionista). Catheter Cardiovasc Interv 87(5): E202-E223. https://doi.org/10.1002/ccd.26379

6. Mehran R, Baber U, Sharma SK, Cohen DJ, Angiolillo DJ, Briguori C, Cha JY, Collier T, Dangas G, Dudek D, Džavík V, Escaned J, Gil R, Gurbel P, Hamm CW, Henry T, Huber K, Kastrati A, Kaul U, Kornowski R, Krucoff M, Kunadian V, Marx SO, Mehta SR, Moliterno D, Ohman EM, Oldroyd K, Sardella G, Sartori S, Shlofmitz R, Steg PG, Weisz G, Witzenbichler B, Han YL, Pocock S, Gibson CM (2019) Ticagrelor with or without aspirin in high-risk patients after PCI. N Engl J Med 381(21):2032-2042. https://doi.org/10.1056/NEJMoa1 908419

7. Schiffer CA, Anderson KC, Bennett CL, Bernstein S, Elting LS, Goldsmith M, Goldstein M, Hume H, McCullough J, McIntyre R, Powell BL, Rainey JM,
Rowley SD, Rebulla P, Troner MB, Wagnon AH, American Society of Clinical Oncology (2001) Platelet transfusion for patients with cancer: clinical practice guidelines of the American Society of Clinical Oncology. J Clin Oncol 19(5):1519-1538. https://doi.org/10.1200/JCO.2001.19.5.1519

8. Yusuf SW, Iliescu C, Bathina JD, Daher IN, Durand JB (2010) Antiplatelet therapy and percutaneous coronary intervention in patients with acute coronary syndrome and thrombocytopenia. Tex Heart Inst J 37(3):336-340

\section{Publisher's Note}

Springer Nature remains neutral with regard to jurisdictional claims in published maps and institutional affiliations.

\section{Submit your manuscript to a SpringerOpen ${ }^{\circ}$ journal and benefit from:}

- Convenient online submission

- Rigorous peer review

- Open access: articles freely available online

High visibility within the field

- Retaining the copyright to your article

Submit your next manuscript at $\boldsymbol{\nabla}$ springeropen.com 